\title{
PENGARUH ALAT PEMASARAN HIJAU TERHADAP PERILAKU PEMBELIAN KONSUMEN
}

\author{
Ni Made Ari Puspa Dewi ${ }^{1}$ \\ Ketut Rahyuda ${ }^{2}$
${ }^{1,2}$ Fakultas Ekonomi dan Bisnis Universitas Udayana, Bali, Indonesia email: aripuspad@yahoo.com

\begin{abstract}
ABSTRAK
Fenomena meningkatnya kesadaran dan kepedulian terhadap kelestarian lingkungan mendorong individu mengonsumsi produk ramah lingkungan membuat perusahaan menerapkan strategi pemasaran hijau. Perusahaan yang mengimplementasikan strategi pemasaran hijau PT. Martina Berto, Tbk produknya Sariayu Martha Tilaar. Tujuan penelitian untuk mengetahui pengaruh alat pemasaran hijau berupa eco label, eco brand, dan environmental advertisement serta variabel yang berpengaruh dominan terhadap perilaku pembelian konsumen pada Sariayu Martha Tilaar. Penelitian menggunakan pendekatan kuantitatif dan dilakukan di Kota Denpasar. Sampel penelitian berjumlah 112 responden dengan metode non-probability sampling teknik purposive sampling. Pengumpulan data melalui wawancara dan kuesioner. Teknik analisis data regresi linear berganda. Hasil penelitian menunjukkan bahwa seluruh hipotesis diterima. Secara parsial eco label, eco brand, dan environmental advertisement berpengaruh positif dan signifikan terhadap perilaku pembelian konsumen. Eco brand merupakan variabel alat pemasaran hijau yang berpengaruh dominan terhadap perilaku pembelian konsumen.
\end{abstract}

Kata kunci: eco label, eco brand, environmental advertisement, dan perilaku pembelian konsumen.

\begin{abstract}
The phenomenon of increasing awareness and concern for environmental sustainability encourages individual to consume environmentally friendly products that make the company implement green marketing strategy. Company that implements the green marketing strategy PT. Martina Berto, Tbk products Sariayu Martha Tilaar. The purpose of study is to determine the effect of green marketing tools in the form of eco label, eco brand, and environmental advertisement and variables dominantly influence consumer buying behavior of Sariayu Martha Tilaar. This research uses quantitative approach and conducted in Denpasar City. The sample study amounted to 112 respondents with nonprobability sampling method of purposive sampling technique. Data collection was interviews and questionnaires. Data analysis techniques multiple linear regression. The results study indicate that all hypotheses are accepted. While the partial eco label, eco brand, and environmental advertisement have a positive and significant impact on consumer purchasing behavior. Eco brand is a variable of green marketing tool that has dominant influence to consumer purchasing behavior.
\end{abstract}

Keywords: eco label, eco brand, environmental advertisement, and consumer purchase behavior. 


\section{PENDAHULUAN}

Pandangan dan pola hidup manusia mulai bergeser seiring dengan meningkatnya kesadaran dan kepedulian terhadap lingkungan (Muslim dan Indriani, 2014). Meningkatnya kesadaran dan kepedulian akan pentingnya kelestarian lingkungan mendorong setiap individu untuk mengonsumsi produk ramah lingkungan (Parawitha dan Rastini, 2016). Hal tersebut membuat perusahaan melakukan perubahan pada strategi pemasarannya yang mulai menerapkan pemasaran berbasis kelestarian lingkungan (Balawera, 2013). Menurut Putripeni dkk. 2014, pemasaran yang berbasis pada kelestarian lingkungan "environmental marketing", merupakan perkembangan baru dalam bidang pemasaran dan merupakan suatu peluang potensial dan strategis yang memiliki keuntungan ganda (multiplier effect), baik bagi pelaku bisnis maupun masyarakat sebagai pengguna. Perusahaan dapat turut berkontribusi dalam mengatasi masalah lingkungan dengan cara aktivitas pemasarannya berbasiskan pada kelestarian lingkungan yang dinamakan dengan konsep pemasaran hijau (Priyantika dan Wardana, 2015).

Pemasaran hijau dalam tujuan memenuhi kebutuhan dan keinginan konsumen harus mampu memahami serta mengerti perilaku konsumen (Prastiyo, 2016). Kotler dan Amstrong (2008:202), menyatakan bahwa berkaitan dengan perilaku konsumen penting diperhatikan konsep pemasaran dimana kunci untuk mewujudkan tujuan organisasi terletak pada kemampuan organisasi dalam menciptakan, memberikan, dan mengomunikasikan nilai pelanggan (customer 
Ni Made Ari Puspa Dewi, Pengaruh Alat...

value) kepada pasar sasarannya secara lebih efektif dibandingkan pesaing. Menurut Suprapti (2010:2), perilaku konsumen didefinisikan sebagai perilaku ditunjukkan oleh konsumen dalam mencari, membeli, menggunakan, mengevaluasi, dan membuang produk yang diharapkan akan memenuhi berbagai kebutuhannya. Perusahaan menerapkan konsep pemasaran dalam menjaga keunggulan bersaing selalu mengamati dan mengidentifikasi apa yang menjadi kebutuhan dan keinginan konsumen (Sharma dan Trivedi, 2016).

Salah satu perusahaan yang aktivitas pemasarannya berkonsepkan pemasaran hijau adalah PT. Martina Berto, Tbk dengan salah satu produknya bernama Sariayu Martha Tilaar. Sariayu Martha Tilaar merupakan produk kecantikan yang baik untuk kesehatan karena berbahan dasar sari-sari tumbuhan (Trisnawati, 2016). Menurut Ekowati dan Saputra (2015), menyatakan bahwa Sariayu Martha Tilaar lebih fokus pada program penggunaan bahan dasar kosmetik yang alami dengan memperhatikan hasil produk yang aman serta ramah lingkungan.

Sariayu Martha Tilaar adalah salah satu brand yang menawarkan produk kecantikan dikenal sebagai natural beauty care, berarti kata natural disini menjadi sangat penting karena menggambarkan produknya dengan bahan baku alami (Trisnawati, 2016). Namun, dalam salah satu penghargaan citra perusahaan di Indonesia, yaitu pada penghargaan Indonesia Most Admired Companies (IMAC), ternyata berdasarkan survei IMAC, Sariayu Martha Tilaar mengalami penurunan 
pada Tahun 2016 dibandingkan 2015. Berikut hasil survei IMAC kategori kosmetik pada Tahun 2015 dan 2016 dapat dilihat pada Tabel 1, sebagai berikut:

Tabel 1.

Indonesia Most Admired Companies (IMAC) Kategori Kosmetik pada Tahun 2015 dan 2016

\begin{tabular}{lcc}
\hline \multicolumn{1}{c}{ Company } & CII 2015 & CII 2016 \\
\hline PT. Martina Berto, Tbk (Sariayu Martha Tilaar) & $1.493(1)$ & $1.121(2)$ \\
& $(\mathrm{E})$ & $(\mathrm{E})$ \\
PT. Mustika Ratu, Tbk & $1.302(2)$ & $1.050(3)$ \\
PT. L'Oreal Indonesia & $(\mathrm{E})$ & $(\mathrm{E})$ \\
PT. Eres Revco (Revlon) & $0.744(3)$ & $0.813(5)$ \\
PT. Paragon Technology and Innovation (Wardah) & $0.733(4)$ & $0.825(4)$ \\
& $0.729(5)$ & $1.191(1)$ \\
\hline
\end{tabular}

Sumber: www.imacaward.com (2015 dan 2016).

Keterangan, (CII) Corporate Image Index); Menyatakan peringkat 1; Menyatakan peringkat 2; Menyatakan peringkat 3; Menyatakan peringkat 4; Menyatakan peringkat 5; Menyatakan predikat excellent.

Berdasarkan Tabel 1 menunjukkan bahwa yang menjadi peringkat pertama dengan predikat excellent berdasarkan IMAC kategori kosmetik pada Tahun 2015 adalah PT. Martina Berto, Tbk dengan produknya Sariayu Martha Tilaar. Tahun 2016, Sariayu Martha Tilaar tetap mendapatkan predikat excellent dalam penghargaan IMAC, akan tetapi Sariayu Martha Tilaar mengalami penurunan menjadi peringkat kedua dibawah PT. Paragon Technology and Innovation dengan produknya Wardah, meskipun Sariayu Martha Tilaar dikenal sebagai produk kosmetik berbahan alami yang berkonsepkan pemasaran hijau. Penurunan citra perusahaan merupakan salah satu hal yang menyebabkan menurunnya perilaku pembelian konsumen terhadap Sariayu Martha Tilaar. 
Alat pemasaran hijau (green marketing tools) merupakan salah satu variabel yang diperhitungkan untuk mengetahui pengaruhnya terhadap perilaku pembelian konsumen (Rahbar dan Wahid, 2011). Elemen-elemen alat pemasaran hijau berupa eco label, eco brand, dan environmental advertisement yang dapat mempengaruhi persepsi dan akan lebih mudah meningkatkan kesadaran atribut dan karakteristik dari produk ramah lingkungan (Delafrooz et al., 2014). Menurut Putranto (2014), alat pemasaran hijau memiliki peran penting dalam meningkatkan perilaku pembelian konsumen terhadap produk ramah lingkungan sehingga mampu mengurangi dampak negatif dari produk-produk sintetis yang dapat merusak lingkungan.

Eco label merupakan salah satu sarana untuk penyampaian informasi yang akurat bagi konsumen mengenai aspek lingkungan suatu produk, komponen atau kemasannya (Ekowati dan Saputra, 2015). Menurut Sharma dan Trivedi (2016), eco label sangat berguna bagi konsumen karena memberikan pengetahuan tentang bahan baku yang digunakan pada produk sehingga konsumen dapat mengambil keputusan untuk membeli produk atau tidak serta membantu konsumen mengidentifikasi produk ramah lingkungan. Menurut Trisnawati (2016), pengemasan Sariayu Martha Tilaar menunjukkan eco label yang memberikan informasi bahwa produknya berbahan alami dan merupakan produk ramah lingkungan.

American Marketing Association (AMA, 2009), mendefinisikan eco brand sebagai nama, istilah, tanda, simbol atau desain yang dimaksudkan untuk mengidentifikasi produk dari satu penjual atau kelompok penjual dan untuk 
membedakan produk dari pesaing. Eco brand pada logo merek Sariayu Martha Tilaar menampilkan gambar wanita yang berada dalam lingkaran dan dibawahnya tercantum slogan "Cantik Alami Seutuhnya" serta memadukan antara warna putih dan hijau. Logo merek Sariayu Martha Tilaar memberikan kesan mengajak seluruh wanita untuk tampil cantik dengan menggunakan produk kosmetik berbahan alami dalam pemenuhan kebutuhan. Selain itu, perpaduan warna putih dan hijau yang digunakan dapat menunjukkan bahwa Sariayu Martha Tilaar merupakan produk yang ramah lingkungan.

Environmental advertisement atau bisa disebut juga sebagai green advertising, memberikan informasi terkait tentang produk ramah lingkungan (Prastiyo, 2016). Green advertising adalah periklanan yang tampilannya berwawasan lingkungan (Ekowati dan Saputra, 2015). Omidna (2015), mendefinisikan green advertising merupakan usaha pemasaran yang dilakukan perusahaan untuk mempromosikan produk dalam meningkatkan perusahaan dengan menekankan pada kelestarian lingkungan.

Environmental advertisement dilakukan Sariayu Martha Tilaar merupakan salah satu bentuk kegiatan periklanan bertujuan untuk menarik konsumen dengan memberikan informasi bahwa produknya merupakan produk ramah lingkungan, seperti pada periklanannya menampilkan warna hijau dan kepedulian terhadap bahan baku yang digunakan. Sariayu Martha Tilaar juga memperhatikan aspek komunikasi melalui media bahwa media saat ini sangat berperan penting dalam memperkenalkan, mempromosikan, menginformasikan suatu produk, dan membangun citra suatu merek. 
Dilihat dari fenomena dan data yang diperoleh, untuk menelusuri serta membuktikan secara empiris tentang pengaruh alat pemasaran hijau terhadap perilaku pembelian konsumen, maka dilakukan penelitian awal. Penelitian awal yang telah dilakukan melalui wawancara berdasarkan kuesioner (terlampir) pada sampel 20 orang responden di Kota Denpasar, menemukan bahwa sebanyak 5 orang $(25 \%)$, menyatakan mengetahui dan menyadari pentingnya penggunaan alat pemasaran hijau berupa eco label, eco brand, dan environmental advertisement pada produk ramah lingkungan, seperti pada produk kosmetik Sariayu Martha Tilaar dalam menentukan keputusan pembelian mereka.

Mereka yakin dan percaya bahwa alat pemasaran hijau mampu menginformasikan, mengidentifikasi serta menunjukkan Sariayu Martha Tilaar sebagai produk yang ramah lingkungan. Namun, sebanyak 15 orang (75\%), menyatakan tidak mengetahui dan menyadari penggunaan alat pemasaran hijau pada Sariayu Martha Tilaar sebagai produk ramah lingkungan, pada kenyataannya menurut data diperoleh Sariayu Martha Tilaar mendapatkan predikat excellent pada penghargaan Indonesia Most Admired Companies (IMAC) kategori kosmetik karena produknya berbahan baku alami dan berkonsepkan ramah lingkungan yang meningkatkan citra perusahaan sehingga mampu meningkatkan perilaku pembelian konsumen.

Selain itu, terdapat penelitian sebelumnya dari penelitian Ekowati dan Saputra (2015), menyatakan bahwa Sariayu Martha Tilaar merupakan produk yang aman bagi kesehatan serta ramah lingkungan. Berdasarkan penelitian awal tersebut, maka perlu dilakukan penelitian lebih lanjut tentang bagaimana pengaruh 
alat pemasaran hijau terhadap perilaku pembelian konsumen, khususnya pada pengguna Sariayu Martha Tilaar di Kota Denpasar.

Menurut hasil penelitian terdahulu dari hasil penelitian Daria dan Sara (2011), yang menyatakan bahwa eco label mampu dalam mempengaruhi perilaku pembelian konsumen. Namun, berbeda dengan hasil penelitian Yulindo (2013), yang menyatakan bahwa label produk tidak berpengaruh secara signifikan terhadap keputusan pembelian konsumen. Hasil penelitian Putranto (2014), juga menyatakan bahwa eco label berpengaruh positif tetapi tidak signifikan terhadap perilaku pembelian aktual konsumen.

Hasil penelitian Delafrooz et al. (2014), tentang pengaruh eco brand terhadap perilaku pembelian konsumen menemukan bahwa terdapat hubungan yang positif dan signifikan. Namun, hasil penelitian Yulindo (2013), menemukan bahwa merek produk tidak berpengaruh signifikan terhadap keputusan pembelian konsumen.

Selanjutnya, penelitian mengenai environmental advertisement terhadap perilaku pembelian konsumen pada hasil penelitian Delafrooz et al. (2014), menemukan bahwa environmental advertisement memiliki hubungan positif dan signifikan terhadap perilaku pembelian konsumen. Namun, bertolak belakang dengan hasil penelitian Rahbar dan Wahid (2011), menemukan bahwa tidak ada hubungan yang signifikan antara environmental advertisement dengan perilaku pembelian konsumen. Hasil penelitian Pawitaningtyas dkk. (2015), juga menemukan bahwa green advertising terbukti memiliki pengaruh positif tetapi tidak signifikan terhadap keputusan pembelian. 
Eco label sebagai alat pemasaran hijau mampu dalam membantu konsumen untuk mengidentifikasi produk ramah lingkungan (Sharma dan Trivedi, 2016). Berdasarkan hasil penelitian Rahbar dan Wahid (2011), menunjukkan bahwa terdapat pengaruh positif dan signifikan dari alat pemasaran hijau, yaitu eco label terhadap perilaku pembelian konsumen. Hasil penelitian Daria dan Sara (2011), menunjukkan bahwa eco label mampu dalam mempengaruhi perilaku pembelian konsumen. Hasil penelitian Delafrooz et al. (2014), menunjukkan bahwa terdapat pengaruh positif dan signifikan antara eco label terhadap perilaku pembelian konsumen. Sejalan dengan hasil penelitian yang ditunjukkan oleh Taufique et al. (2016), bahwa pengetahuan tentang eco label positif mempengaruhi perilaku lingkungan dan perilaku konsumen.

Begitu pula dengan hasil penelitian Prastiyo (2016), yang menunjukkan bahwa eco label berpengaruh positif dan signifikan terhadap perilaku pembelian konsumen, apabila pelaksanaan eco label meningkat maka akan diikuti oleh meningkatnya perilaku pembelian konsumen. Namun, hasil penelitian tersebut berbeda dengan hasil penelitian Yulindo (2013), yang menunjukkan bahwa label produk tidak berpengaruh secara signifikan terhadap keputusan pembelian konsumen pada green product cosmetics Sariayu Martha Tilaar di Kota Padang dengan nilai signifikan sebesar 0,254 >0,05. Hal ini berarti label produk tidak menimbulkan hasrat konsumen untuk membeli kosmetik Sariayu Martha Tilaar. Begitu pula dengan hasil penelitian Putranto (2014), yang menunjukkan bahwa eco label berpengaruh positif tetapi tidak signifikan terhadap perilaku pembelian aktual konsumen pada produk lampu Philips di Yogyakarta. 
Hasil penelitian sebelumnya lebih banyak ditemukan bahwa eco label berpengaruh positif dan signifikan terhadap perilaku pembelian konsumen, maka dirumuskan hipotesis, sebagai berikut:

$\mathrm{H}_{1}$ : Eco label berpengaruh positif dan signifikan terhadap perilaku pembelian konsumen.

Eco brand merupakan nama, istilah, tanda, simbol atau desain produk yang aman bagi lingkungan (Prastiyo, 2016). Menurut Rahbar dan Wahid (2011), mengungkapkan bahwa penelitian sebelumnya di negara-negara barat mendukung gagasan bahwa konsumen di Amerika Serikat dan Jerman mengambil tindakan positif untuk produk ramah lingkungan dan terdapat pengaruh yang positif dan signifikan dari alat pemasaran hijau, yaitu eco brand terhadap perilaku pembelian konsumen. Berdasarkan hasil penelitian dari Delafrooz et al. (2014), menemukan bahwa eco brand memiliki hubungan positif dan signifikan terhadap perilaku pembelian konsumen. Sejalan dengan hasil penelitian yang ditunjukkan oleh Sharma dan Trivedi (2016), menemukan bahwa eco brand merupakan variabel yang penting bagi pemasar hijau dan eco brand berpengaruh signifikan terhadap perilaku pembelian konsumen produk hijau.

Ini berarti semakin kuat eco brand, maka perilaku pembelian konsumen pada produk akan semakin meningkat. Namun, hasil penelitian Yulindo (2013), menemukan bahwa merek produk (X) tidak berpengaruh signifikan terhadap keputusan pembelian (Y) green product cosmetics Sariayu Martha Tilaar di Kota Padang, dengan nilai signifikan sebesar 0,548 > 0,05. Hal ini berarti bahwa merek 
produk tidak mempengaruhi keputusan pembelian kosmetik Sariayu Martha Tilaar di Kota Padang. Dapat dirumuskan hipotesis, sebagai berikut:

$\mathrm{H}_{2}$ : Eco brand berpengaruh positif dan signifikan terhadap perilaku pembelian konsumen.

Environmental advertisement atau bisa disebut juga sebagai green advertising, bertujuan memberikan informasi kepada konsumen tentang produk ramah lingkungan (Prastiyo, 2016). Berdasarkan hasil penelitian dari Delafrooz et al. (2014), menyatakan bahwa environmental advertisement memiliki hubungan positif dan signifikan terhadap perilaku pembelian konsumen. Menurut hasil penelitian Anjani dan Aksari (2016), green advertising secara signifikan berpengaruh positif terhadap perilaku pembelian produk hijau. Ini berarti semakin sering melakukan green advertising, maka perilaku pembelian produk hijau akan semakin meningkat.

Sejalan dengan hasil penelitian Mantiaha (2016), menyatakan bahwa pemasaran hijau diwakili oleh green promotion yang memiliki pengaruh positif dan signifikan terhadap perilaku pembelian konsumen. Begitu pula dengan hasil penelitian yang ditunjukkan oleh Sharma dan Trivedi (2016), menyatakan bahwa green advertising merupakan salah satu variabel yang penting bagi pemasar hijau dan green advertising berpengaruh signifikan terhadap perilaku pembelian konsumen produk hijau.

Hasil penelitian tersebut bertolak belakang dengan hasil penelitian Rahbar dan Wahid (2011), yang menyatakan bahwa tidak ada hubungan yang signifikan 
antara environmental advertisement dengan perilaku pembelian konsumen di Penang Malaysia. Beberapa masyarakat di Penang Malaysia meyakini bahwa environmental advertisement meningkatkan pengetahuan mereka tentang produk hijau dan memberikan keyakinan dalam membuat keputusan pembelian. Namun, keyakinan yang mereka miliki tidak berpengaruh terhadap perilaku pembelian mereka pada produk hijau. Hasil penelitian Pawitaningtyas dkk. (2015), juga menyatakan bahwa green advertising terbukti berpengaruh positif tetapi tidak signifikan dalam meningkatkan konsumen melakukan keputusan pembelian.

Hasil penelitian sebelumnya lebih banyak ditemukan bahwa environmental advertisement berpengaruh positif dan signifikan terhadap perilaku pembelian konsumen, maka dirumuskan hipotesis, sebagai berikut:

$\mathrm{H}_{3}$ : Environmental advertisement berpengaruh positif dan signifikan terhadap perilaku pembelian konsumen.

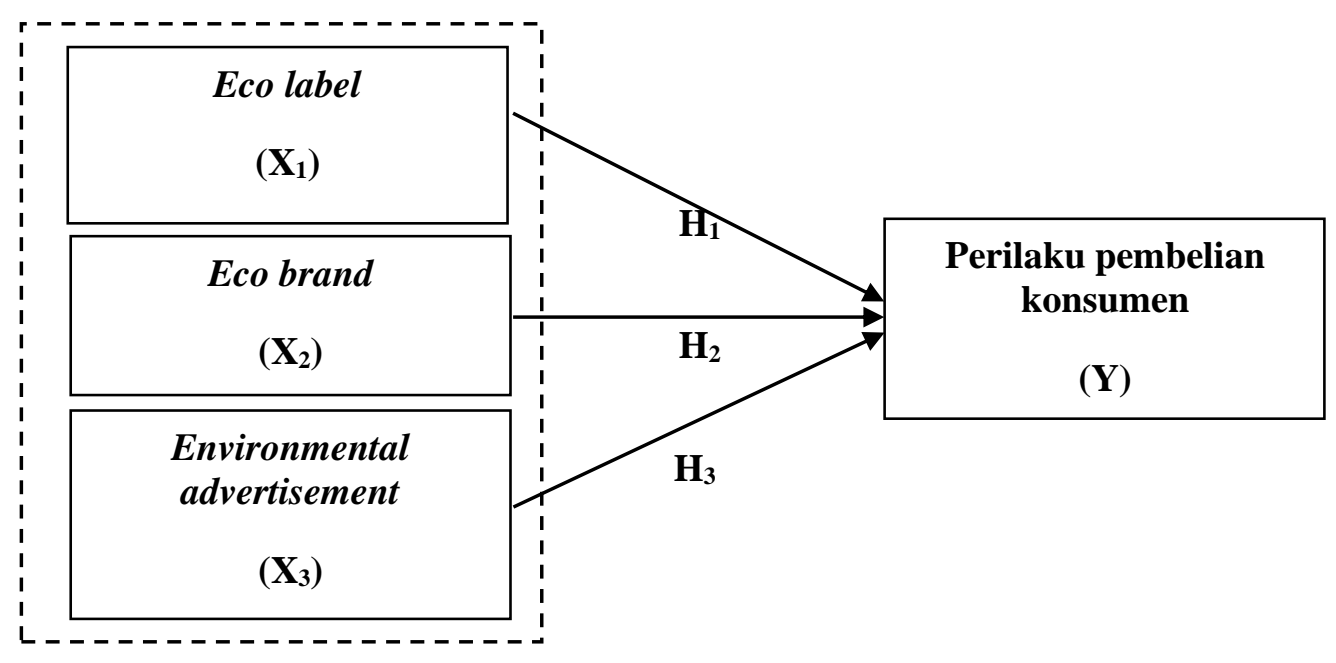

Gambar 1. Kerangka Konsep Penelitian. 


\section{METODE PENELITIAN}

Pendekatan yang digunakan dalam penelitian ini adalah pendekatan kuantitatif. Penggunaan pendekatan penelitian kuantitatif karena dalam penelitian ini berusaha untuk menemukan pengaruh secara langsung dari tiap variabel elemen-elemen alat pemasaran hijau (eco label, eco brand, dan environmental advertisement) terhadap perilaku pembelian konsumen, khususnya pada pengguna Sariayu Martha Tilaar di Kota Denpasar. Jenis penelitian yang akan digunakan bersifat kausal dengan menggunakan kuesioner yang diberikan kepada responden untuk memperoleh data yang dibutuhkan.

Lokasi penelitian ini dilakukan di Kota Denpasar. Pemilihan Kota Denpasar sebagai lokasi penelitian karena Kota Denpasar merupakan daerah yang sebagian besar penduduknya memiliki tingkat pendidikan tinggi. Subyek dalam penelitian ini adalah pengguna Sariayu Martha Tilaar yang bertempat tinggal di Kota Denpasar dan obyek dalam penelitian ini adalah alat pemasaran hijau (eco label, eco brand, dan environmental advertisement) terhadap perilaku pembelian konsumen.

Alat pemasaran hijau (X) merupakan alat yang digunakan bertujuan untuk mengidentifikasi produk ramah lingkungan dan mempengaruhi perilaku konsumen guna meningkatkan perilaku pembelian konsumen terhadap produk ramah lingkungan, khususnya pada pengguna Sariayu Martha Tilaar. Menurut Rahbar dan Wahid (2011), Delafrooz et al. (2014), serta Putranto (2014), elemenelemen dari alat pemasaran hijau, sebagai berikut: 
Eco label $\left(\mathrm{X}_{1}\right)$ adalah label Sariayu Martha Tilaar yang memberikan informasi kepada konsumen tentang bahan alami yang digunakan dan menunjukkan produk ramah lingkungan. Eco brand $\left(\mathrm{X}_{2}\right)$ adalah nama atau simbol yang menunjukkan Sariayu Martha Tilaar merupakan produk yang aman bagi kesehatan serta lingkungan.

Environmental advertisement $\left(\mathrm{X}_{3}\right)$ adalah strategi pemasaran hijau melalui promosi periklanan yang bertujuan mempengaruhi dan membujuk konsumen untuk menggunakan Sariayu Martha Tilaar sebagai produk ramah lingkungan dengan menekankan pada kelestarian lingkungan.

Tabel 2.

Variabel dan Indikator

\begin{tabular}{|c|c|c|c|}
\hline \multicolumn{2}{|c|}{ Variabel } & Indikator & Sumber \\
\hline $\begin{array}{l}\text { Bebas } \\
(\mathbf{X})\end{array}$ & $\begin{array}{l}\text { Eco label } \\
\qquad\left(\mathrm{X}_{1}\right)\end{array}$ & $\begin{array}{l}\text { Kesadaran }\left(\mathrm{X}_{1.1}\right) \\
\text { Mudah dikenali }\left(\mathrm{X}_{1.2}\right) \\
\text { Kepercayaan }\left(\mathrm{X}_{1.3}\right)\end{array}$ & $\begin{array}{l}\text { Rahbar dan Wahid (2011), } \\
\text { Muslim dan Indriani (2014) } \\
\text { serta Prastiyo (2016). }\end{array}$ \\
\hline & $\begin{array}{l}\text { Eco brand } \\
\qquad\left(\mathrm{X}_{2}\right)\end{array}$ & $\begin{array}{l}\text { Kesadaran }\left(\mathrm{X}_{2.1}\right) \\
\text { Keandalan }\left(\mathrm{X}_{2.2}\right) \\
\text { Daya tarik }\left(\mathrm{X}_{2.3}\right)\end{array}$ & $\begin{array}{l}\text { Rahbar dan Wahid (2011), } \\
\text { Anjani dan Aksari (2016) } \\
\text { serta Prastiyo (2016). }\end{array}$ \\
\hline & $\begin{array}{l}\text { Environmental } \\
\text { advertisement } \\
\qquad\left(\mathrm{X}_{3}\right)\end{array}$ & $\begin{array}{l}\text { Media yang tepat }\left(\mathrm{X}_{3.1}\right) \\
\text { Membangun citra }\left(\mathrm{X}_{3.2}\right) \\
\text { Iklan sebagai informasi }\left(\mathrm{X}_{3.3}\right)\end{array}$ & $\begin{array}{l}\text { Rahbar dan Wahid (2011), } \\
\text { Kong et al. (2014) serta } \\
\text { Prastiyo (2016). }\end{array}$ \\
\hline Terikat (Y) & $\begin{array}{l}\text { Perilaku } \\
\text { pembelian } \\
\text { konsumen } \\
\text { (Y) }\end{array}$ & $\begin{array}{l}\text { Rasa ingin membeli }\left(\mathrm{Y}_{1}\right) \\
\text { Pencarian informasi }\left(\mathrm{Y}_{2}\right) \\
\text { Pilihan alternatif }\left(\mathrm{Y}_{3}\right) \\
\text { Rasa yakin membeli }\left(\mathrm{Y}_{4}\right) \\
\text { Perilaku pascapembelian }\left(\mathrm{Y}_{5}\right)\end{array}$ & $\begin{array}{c}\text { Kotler dan Amstrong } \\
\text { (2008:179), Anjani dan } \\
\text { Aksari (2016) serta Prastiyo } \\
\text { (2016). }\end{array}$ \\
\hline
\end{tabular}

Sumber: Data primer, diolah (2017). 
Perilaku pembelian konsumen (Y) adalah kegiatan dan tindakan konsumen terkait tentang pembelian Sariayu Martha Tilaar dalam proses pengambilan keputusan untuk memenuhi kebutuhan dan keinginannya. Menurut Kotler dan Amstrong (2008:179), Anjani dan Aksari (2016), dan Prastiyo (2016), indikatorindikator perilaku pembelian konsumen, sebagai berikut: Rasa ingin membeli $\left(\mathrm{Y}_{1}\right)$, yaitu ketertarikan konsumen dalam membeli Sariayu Martha Tilaar. Pencarian informasi $\left(\mathrm{Y}_{2}\right)$, yaitu tindakan konsumen dalam memperoleh informasi tentang kegunaan dan manfaat Sariayu Martha Tilaar. Pilihan alternatif $\left(\mathrm{Y}_{3}\right)$, yaitu pilihan alternatif terpilih dari berbagai pilihan alternatif lain yang ditawarkan. Rasa yakin membeli $\left(\mathrm{Y}_{4}\right)$, yaitu keyakinan konsumen dalam menentukan pilihan produk yang akan dibeli. Perilaku pascapembelian $\left(\mathrm{Y}_{5}\right)$, yaitu tindakan konsumen tentang kecocokan dan ketidakcocokan setelah membeli Sariayu Martha Tilaar.

Populasi dalam penelitian ini adalah pengguna Sariayu Martha Tilaar yang bertempat tinggal di Kota Denpasar dengan jumlah populasi yang tidak diketahui secara pasti atau tidak terbatas (infinite). Sampel yang digunakan dalam penelitian ini adalah pengguna Sariayu Martha Tilaar di Kota Denpasar.

Penelitian ini menggunakan metode penentuan sampel non-probability sampling, dengan kriteria yang digunakan dalam memilih responden adalah berdasarkan ketentuan, sebagai berikut: responden berpendidikan minimal SMA/Sederajat, bertempat tinggal di Kota Denpasar, dan yang sudah pernah melakukan pembelian Sariayu Martha Tilaar di Kota Denpasar. 


\section{HASIL DAN PEMBAHASAN}

Hasil uji validitas instrumen penelitian disajikan pada Tabel 3. Hasil uji validitas instrumen penelitian, disajikan pada Tabel 3 yang menunjukkan bahwa seluruh indikator pernyataan dalam variabel dari alat pemasaran hijau, yaitu eco label $\left(\mathrm{X}_{1}\right)$, eco brand $\left(\mathrm{X}_{2}\right)$, dan environmental advertisement $\left(\mathrm{X}_{3}\right)$ serta perilaku pembelian konsumen (Y) memiliki koefisien korelasi yang lebih besar dari 0,30 sehingga seluruh indikator tersebut telah memenuhi syarat validitas data. Hal ini berarti pernyataan-pernyataan pada kuesioner mampu mengungkapkan apa yang diukur oleh kuesioner tersebut.

Tabel 3.

Hasil Uji Validitas Instrumen

\begin{tabular}{ccccc}
\hline No & Variabel & Indikator & Koefisien Korelasi & Keterangan \\
\hline \multirow{2}{*}{$\mathbf{1}$} & Eco label & $\mathrm{X}_{1.1}$ & 0,970 & Valid \\
& $\left(\mathrm{X}_{1}\right)$ & $\mathrm{X}_{1.2}$ & 0,959 & Valid \\
& Eco brand & $\mathrm{X}_{1.3}$ & 0,960 & Valid \\
$\mathbf{2}$ & $\left(\mathrm{X}_{2}\right)$ & $\mathrm{X}_{2.1}$ & 0,905 & Valid \\
& Environmental & $\mathrm{X}_{2.2}$ & 0,979 & Valid \\
& advertisement & $\mathrm{X}_{2.3}$ & 0,935 & Valid \\
$\mathbf{3}$ & $\left(\mathrm{X}_{3}\right)$ & $\mathrm{X}_{3.1}$ & 0,951 & Valid \\
& & $\mathrm{X}_{3.3}$ & 0,924 & Valid \\
& & $\mathrm{Y}_{1.1}$ & 0,955 & Valid \\
& Perilaku pembelian & $\mathrm{Y}_{1.2}$ & 0,909 & Valid \\
$\mathbf{4}$ & konsumen & $\mathrm{Y}_{1.3}$ & 0,889 & Valid \\
& $(\mathrm{Y})$ & $\mathrm{Y}_{1.4}$ & 0,844 & Valid \\
& & $\mathrm{Y}_{1.5}$ & 0,843 & Valid \\
& & & 0,910 & Valid \\
\hline
\end{tabular}

Sumber: data primer diolah (2017).

Hasil uji reliabilitas instrumen penelitian, disajikan pada Tabel 4 yang menunjukkan bahwa instrumen penelitian, yaitu variabel dari alat pemasaran hijau berupa eco label $\left(\mathrm{X}_{1}\right)$, eco brand $\left(\mathrm{X}_{2}\right)$, dan environmental advertisement $\left(\mathrm{X}_{3}\right)$ serta perilaku pembelian konsumen (Y) memiliki koefisien Cronbach's Alpha lebih 
besar dari 0,60 sehingga pernyataan pada kuesioner tersebut reliabel. Hasil uji validitas instrumen dinyatakan valid, begitu pula dengan hasil uji reliabilitas instrumen dinyatakan reliabel sehingga seluruh instrumen dapat digunakan dalam analisis.

Tabel 4.

Hasil Uji Reliabilitas Instrumen

\begin{tabular}{lcc}
\hline \multicolumn{1}{c}{ Variabel } & Cronbach's Alpha & Keterangan \\
\hline Eco label $\left(\mathbf{X}_{1}\right)$ & 0,960 & Reliabel \\
Eco brand $\left(\mathbf{X}_{2}\right)$ & 0,931 & Reliabel \\
Environmental advertisement $\left(\mathbf{X}_{3}\right)$ & 0,937 & Reliabel \\
Perilaku pembelian konsumen $(\mathbf{Y})$ & 0,926 & Reliabel \\
\hline
\end{tabular}

Sumber: data primer diolah, (2017).

Variabel eco label merupakan variabel bebas dari alat pemasaran hijau, terdiri dari tiga indikator yang dirangkai dalam pernyataan-pernyataan dan diukur menggunakan Skala Likert terdiri 5 poin. Berikut adalah tanggapan dari responden terhadap pernyataan tersebut.

Tabel 5.

Distribusi Jawaban Responden Terhadap Indikator Variabel Eco Label

\begin{tabular}{|c|c|c|c|c|c|c|c|c|}
\hline \multirow[t]{3}{*}{ No } & \multirow[t]{3}{*}{ Pernyataan } & \multicolumn{5}{|c|}{ Klasifikasi Jawaban } & \multirow{3}{*}{$\begin{array}{l}\text { Rata- } \\
\text { rata }\end{array}$} & \multirow[t]{3}{*}{ Ket. } \\
\hline & & STS & TS & $\mathbf{N}$ & $\mathbf{S}$ & SS & & \\
\hline & & 1 & 2 & 3 & 4 & 5 & & \\
\hline 1 & $\begin{array}{l}\text { Saya memiliki kesadaran } \\
\text { akan pentingnya logo pada } \\
\text { Sariayu Martha Tilaar yang } \\
\text { menginformasikan produk } \\
\text { ramah lingkungan. }\end{array}$ & 0 & 4 & 21 & 54 & 33 & 4,04 & Setuju \\
\hline \multirow[t]{2}{*}{2} & $\begin{array}{llr}\text { Saya mudah dalam } \\
\text { mengenali logo pada Sariayu }\end{array}$ & 0 & 10 & 27 & 53 & 22 & 3,78 & Setuju \\
\hline & $\begin{array}{l}\text { Martha Tilaar yang } \\
\text { menunjukkan produk ramah } \\
\text { lingkungan. }\end{array}$ & & & & & & & \\
\hline \multirow[t]{2}{*}{3} & $\begin{array}{l}\text { Saya mempercayai informasi } \\
\text { yang tertera pada logo bahwa } \\
\text { Sariayu Martha Tilaar adalah } \\
\text { produk ramah lingkungan. }\end{array}$ & 0 & 1 & 29 & 57 & 25 & 3,95 & Setuju \\
\hline & Total Rata & ata $S k$ & & & & & 3,92 & Setuju \\
\hline
\end{tabular}


Sumber:data primer diolah, (2017).

Tabel 5 menunjukkan bahwa rata-rata jawaban tertinggi responden diperoleh pada pernyataan "Saya memiliki kesadaran akan pentingnya logo pada Sariayu Martha Tilaar yang menginformasikan produk ramah lingkungan" dengan nilai rata-rata sebesar 4,04. Pada pernyataan tersebut, 3,6 persen responden menjawab tidak setuju, 18,4 persen responden menjawab netral, 48,2 persen responden menjawab setuju, dan 29,5 persen responden menjawab sangat setuju dengan pernyataan tersebut.

Skor rata-rata terendah dengan nilai rata-rata sebesar 3,78 diperoleh pada pernyataan "Saya mudah dalam mengenali logo pada Sariayu Martha Tilaar yang menunjukkan produk ramah lingkungan". Pada pernyataan tersebut, 8,9 persen responden menjawab tidak setuju, 24,1 persen responden menjawab netral, 47,3 persen responden menjawab setuju, dan 19,6 persen responden menjawab sangat setuju dengan pernyataan tersebut.

Berdasarkan data tersebut dapat ditentukan rata-rata nilai variabel eco label adalah sebesar 3,92. Dengan demikian, secara umum responden setuju bahwa Sariayu Martha Tilaar merupakan produk ramah lingkungan dilihat dari logo yang dimiliki Sariayu Martha Tilaar.

Variabel eco brand merupakan variabel bebas dari alat pemasaran hijau, terdiri dari tiga indikator yang dirangkai dalam pernyataan-pernyataan dan diukur menggunakan Skala Likert terdiri 5 poin. Berikut adalah tanggapan dari responden terhadap pernyataan tersebut. 
Rata-rata jawaban tertinggi pengguna Sariayu Martha Tilaar dilihat dari Tabel 6 terdapat pada pernyataan "Merek yang digunakan Sariayu Martha Tilaar menjadi daya tarik yang kuat", dengan nilai sebesar 3,82. Pada pernyataan tersebut, responden yang menjawab tidak setuju sebesar 6,3 persen, responden yang menjawab netral sebesar 24,1 persen, 50,9 persen responden yang menjawab setuju, dan responden yang menjawab sangat setuju adalah sebesar 18,8 persen.

Rata-rata jawaban pengguna Sariayu Martha Tilaar pada pernyataan "Saya menyadari akan pentingnya kekuatan merek Sariayu Martha Tilaar yang menunjukkan produk ramah lingkungan", sebesar 3,79. Pada pernyataan tersebut, responden yang menjawab tidak setuju sebesar 6,3 persen, responden yang menjawab netral sebesar 25,0 persen, responden yang menjawab setuju sebesar 52,7 persen, dan responden yang menjawab sangat setuju sebesar 16,1 persen.

Tabel 6.

Distribusi Jawaban Responden Terhadap Indikator Variabel Eco Brand

\begin{tabular}{|c|c|c|c|c|c|c|c|c|}
\hline \multirow[t]{3}{*}{ No } & \multirow[t]{3}{*}{ Pernyataan } & \multicolumn{5}{|c|}{ Klasifikasi Jawaban } & \multirow{3}{*}{$\begin{array}{c}\text { Rata- } \\
\text { rata }\end{array}$} & \multirow[t]{3}{*}{ Ket. } \\
\hline & & STS & TS & $\mathbf{N}$ & $\mathbf{S}$ & SS & & \\
\hline & & 1 & 2 & 3 & 4 & 5 & & \\
\hline 1 & $\begin{array}{l}\text { Saya menyadari akan pentingnya } \\
\text { kekuatan merek Sariayu Martha } \\
\text { Tilaar yang menunjukkan } \\
\text { produk ramah lingkungan. }\end{array}$ & 0 & 7 & 28 & 59 & 18 & 3,79 & Setuju \\
\hline 2 & $\begin{array}{l}\text { Merek Sariayu Martha Tilaar } \\
\text { memberikan keyakinan tentang } \\
\text { keandalan produk yang ramah } \\
\text { lingkungan. }\end{array}$ & 0 & 6 & 27 & 63 & 16 & 3,79 & Setuju \\
\hline 3 & $\begin{array}{l}\text { Merek yang digunakan Sariayu } \\
\text { Martha Tilaar menjadi daya tarik } \\
\text { yang kuat. }\end{array}$ & 0 & 7 & 27 & 57 & 21 & 3,82 & Setuju \\
\hline & Total Rata-r & a Skol & & & & & $\mathbf{3 , 8 0}$ & Setuju \\
\hline
\end{tabular}

Sumber:data primer diolah, (2017).

Rata-rata jawaban pengguna Sariayu Martha Tilaar pada pernyataan "Merek Sariayu Martha Tilaar memberikan keyakinan tentang keandalan produk yang ramah lingkungan", sebesar 3,79. Pada pernyataan tersebut, responden yang 
menjawab tidak setuju sebesar 5,4, responden yang menjawab netral sebesar 24,1 persen, responden yang menjawab setuju sebesar 56,3 persen dan responden yang menjawab sangat setuju sebesar 14,3 persen.

Berdasarkan data tersebut dapat ditentukan rata-rata nilai variabel eco brand adalah sebesar 3,80. Dengan demikian, dapat dinyatakan bahwa secara umum responden setuju bahwa Sariayu Martha Tilaar merupakan produk ramah lingkungan dilihat dari brand yang dimiliki Sariayu Martha Tilaar.

Variabel environmental advertisement merupakan variabel bebas dari alat pemasaran hijau, terdiri dari tiga indikator yang dirangkai dalam pernyataanpernyataan dan diukur menggunakan Skala Likert terdiri 5 poin. Berikut adalah tanggapan dari responden terhadap pernyataan tersebut.

Tabel 7.

Distribusi Jawaban Responden Terhadap Indikator Variabel Environmental Advertisement

\begin{tabular}{|c|c|c|c|c|c|c|c|c|}
\hline \multirow[t]{3}{*}{ No } & \multirow[t]{3}{*}{ Pernyataan } & \multicolumn{5}{|c|}{ Klasifikasi Jawaban } & \multirow{3}{*}{$\begin{array}{c}\text { Rata- } \\
\text { rata }\end{array}$} & \multirow[t]{3}{*}{ Ket. } \\
\hline & & STS & TS & $\mathbf{N}$ & $\mathbf{S}$ & SS & & \\
\hline & & 1 & 2 & 3 & 4 & 5 & & \\
\hline 1 & 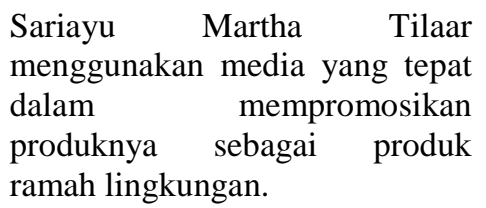 & 0 & 10 & 26 & 52 & 24 & 3,80 & Setuju \\
\hline 2 & $\begin{array}{lcr}\text { Periklanan yang } & \text { dilakukan } \\
\text { Sariayu } \quad \text { Martha } & \text { Tilaar } \\
\text { membangun citra sebagai produk } \\
\text { ramah lingkungan. }\end{array}$ & 0 & 12 & 27 & 54 & 19 & 3,71 & Setuju \\
\hline 3 & $\begin{array}{l}\text { Periklanan Sariayu Martha } \\
\text { Tilaar mampu memberikan } \\
\text { informasi yang dapat menjadi } \\
\text { panduan untuk membuat } \\
\text { keputusan pembelian. }\end{array}$ & 0 & 11 & 25 & 53 & 23 & 3,79 & Setuju \\
\hline & Total Rata-ra & a Skor & & & & & 3,77 & Setuju \\
\hline
\end{tabular}

Sumber: data primer diolah, (2017).

Tabel 7 menunjukkan bahwa rata-rata jawaban tertinggi responden diperoleh pada pernyataan "Sariayu Martha Tilaar menggunakan media yang tepat dalam 
mempromosikan produknya sebagai produk ramah lingkungan", dengan nilai ratarata sebesar 3,80. Pada pernyataan tersebut, 8,9 persen responden menjawab tidak setuju, 23,2 persen responden menjawab netral, 46,4 persen responden menjawab setuju, dan 21,4 persen responden menjawab sangat setuju dengan pernyataan tersebut.

Skor rata-rata terendah dengan nilai rata-rata sebesar 3,71 diperoleh pada pernyataan "Periklanan yang dilakukan Sariayu Martha Tilaar membangun citra sebagai produk ramah lingkungan". Pada pernyataan tersebut, 10,7 persen responden menjawab tidak setuju, 24,1 persen responden menjawab netral, 48,2 persen responden menjawab setuju, dan 17,0 persen responden menjawab sangat setuju dengan pernyataan tersebut.

Berdasarkan data tersebut dapat ditentukan rata-rata nilai variabel environmental advertisement adalah sebesar 3,77. Dengan demikian, secara umum responden setuju bahwa Sariayu Martha Tilaar merupakan produk ramah lingkungan dilihat dari pelaksanaan environmental advertisement yang dilakukan Sariayu Martha Tilaar.

Variabel perilaku pembelian konsumen merupakan variabel terikat, terdiri dari lima indikator yang dirangkai dalam pernyataan-pernyataan dan diukur menggunakan Skala Likert terdiri 5 poin. Berikut adalah tanggapan dari responden terhadap pernyataan tersebut.

Tabel 8 menunjukkan bahwa rata-rata jawaban tertinggi responden diperoleh pada pernyataan "Saya memiliki harapan memperoleh kecocokan setelah melakukan pembelian Sariayu Martha Tilaar", dengan nilai rata-rata sebesar 3,92. 
Pada pernyataan tersebut, 5,4 persen responden menjawab tidak setuju, 22,3 persen responden menjawab netral, 47,3 persen responden menjawab setuju, dan 25,0 persen responden menjawab sangat setuju dengan pernyataan tersebut.

Skor rata-rata terendah dengan nilai rata-rata sebesar 3,77 diperoleh pada pernyataan "Saya melakukan pencarian informasi tentang Sariayu Martha Tilaar untuk mengetahui kegunaan dan manfaatnya". Pada pernyataan tersebut, 8,9 persen responden menjawab tidak setuju, 24,1 persen responden menjawab netral, 48,2 persen responden menjawab setuju, dan 18,8 persen responden menjawab sangat setuju dengan pernyataan tersebut.

Tabel 8.

Distribusi Jawaban Responden Terhadap Indikator Variabel Perilaku Pembelian Konsumen

\begin{tabular}{|c|c|c|c|c|c|c|c|c|}
\hline \multirow[t]{3}{*}{ No } & \multirow[t]{3}{*}{ Pernyataan } & \multicolumn{5}{|c|}{ Klasifikasi Jawaban } & \multirow{3}{*}{$\begin{array}{c}\text { Rata- } \\
\text { rata }\end{array}$} & \multirow[t]{3}{*}{ Ket. } \\
\hline & & STS & TS & $\mathbf{N}$ & $\mathbf{S}$ & SS & & \\
\hline & & 1 & 2 & 3 & 4 & 5 & & \\
\hline 1 & \begin{tabular}{lll}
\multicolumn{2}{l}{ Saya merasakan keputusan } \\
membeli Sariayu & Martha \\
Tilaar sesuai & dengan \\
keinginan. &
\end{tabular} & 0 & 5 & 29 & 49 & 29 & 3,91 & Setuju \\
\hline 2 & $\begin{array}{l}\text { Saya melakukan pencarian } \\
\text { informasi tentang Sariayu } \\
\text { Martha Tilaar untuk } \\
\text { mengetahui kegunaan dan } \\
\text { manfaatnya. }\end{array}$ & 0 & 10 & 27 & 54 & 21 & 3,77 & Setuju \\
\hline 3 & $\begin{array}{l}\text { Saya dihadapkan kepada } \\
\text { beberapa alternatif pilihan } \\
\text { produk dari berbagai } \\
\text { pilihan lainnya. }\end{array}$ & 0 & 3 & 31 & 55 & 23 & 3,88 & Setuju \\
\hline 4 & $\begin{array}{l}\text { Saya berniat untuk } \\
\text { membeli Sariayu Martha } \\
\text { Tilaar setelah memperoleh } \\
\text { keyakinan. }\end{array}$ & 0 & 4 & 28 & 57 & 23 & 3,88 & Setuju \\
\hline 5 & $\begin{array}{l}\text { Saya memiliki harapan } \\
\text { memperoleh kecocokan } \\
\text { setelah melakukan } \\
\text { pembelian Sariayu Martha } \\
\text { Tilaar. }\end{array}$ & 0 & 6 & 25 & 53 & 28 & 3,92 & Setuju \\
\hline & $\begin{array}{r}\text { Total Rata } \\
\end{array}$ & ata $S k$ & & & & & 3,87 & Setuju \\
\hline
\end{tabular}

Sumber: data primer diolah, (2017). 
Berdasarkan data tersebut dapat ditentukan rata-rata nilai variabel perilaku pembelian konsumen adalah sebesar 3,87. Dengan demikian, secara umum responden setuju bahwa Sariayu Martha Tilaar merupakan produk ramah lingkungan yang mampu mendorong perilaku pembelian konsumen.

Analisis regresi linear berganda digunakan untuk mengetahui pengaruh alat pemasaran hijau (eco label, eco brand, dan environmental advertisement) terhadap perilaku pembelian konsumen. Berdasarkan Tabel 9, maka diperoleh persamaan regresi linear berganda, sebagai berikut:

$$
\mathrm{Y}=0,247 \mathrm{X}_{1}+0,408 \mathrm{X}_{2}+0,292 \mathrm{X}_{3}+\mathrm{ei}
$$

Tabel 9.

Hasil Regresi Linear Berganda

\begin{tabular}{|c|c|c|c|c|c|}
\hline \multirow[t]{3}{*}{ Model } & \multicolumn{2}{|c|}{$\begin{array}{c}\text { Unstandardized } \\
\text { Coeficients }\end{array}$} & \multirow{2}{*}{$\begin{array}{c}\text { Standardized } \\
\text { Coeficients }\end{array}$} & \multirow[t]{2}{*}{$\mathbf{t}$} & \multirow[t]{2}{*}{ Sig. } \\
\hline & $\mathbf{B}$ & Std. Error & & & \\
\hline & 2,475 & 1,107 & & 2,236 & 0,027 \\
\hline Konstanta & 0,397 & 0,119 & 0,247 & 3,348 & 0,001 \\
\hline Eco label $\left(\mathbf{X}_{1}\right)$ & 0,657 & 0,136 & 0,408 & 4,831 & 0,000 \\
\hline $\begin{array}{l}\text { Eco brand }\left(\mathrm{X}_{2}\right) \\
\text { Environmental } \\
\text { advertisement }(\end{array}$ & 0,417 & 0,107 & 0,292 & 3,890 & 0,000 \\
\hline R Square & & & & & $\mathbf{0 , 6 9 7}$ \\
\hline F Statistik & & & & & 82,697 \\
\hline Signifikansi & & & & & $\mathbf{0 , 0 0 0}$ \\
\hline
\end{tabular}

Sumber: data primer diolah, (2017).

Nilai koefisien determinasi total sebesar 0,697 yang berarti bahwa sebesar 69,7 persen variabel perilaku pembelian konsumen dipengaruhi oleh variabel alat pemasaran hijau, yaitu eco label, eco brand, dan environmental advertisement, sedangkan sisanya sebesar 30,3 persen dijelaskan oleh variabel lain yang tidak dijelaskan dalam analisis ini (penelitian ini). 
Hasil regresi menunjukkan bahwa nilai dari F hitung sebesar 82,697 dengan nilai signifikansi 0,000 (kurang dari 0,05), maka berarti terdapat pengaruh yang signifikan antara alat pemasaran hijau, yaitu eco label, eco brand, dan environmental advertisement terhadap perilaku pembelian konsumen pada Sariayu Martha Tilaar di Kota Denpasar.

Berdasarkan nilai signifikansi t untuk eco label sebesar 0,001 dengan nilai koefisien beta 0,247 yang berarti bahwa eco label berpengaruh positif dan signifikan terhadap perilaku pembelian konsumen pada Sariayu Martha Tilaar di Kota Denpasar. Nilai signifikansi t untuk eco brand sebesar 0,000 dengan nilai koefisien beta 0,408 yang berarti bahwa eco brand berpengaruh positif dan signifikan terhadap perilaku pembelian konsumen pada Sariayu Martha Tilaar di Kota Denpasar. Selanjutnya, nilai signifikansi t untuk environmental advertisement sebesar 0,000 dengan nilai koefisien beta 0,292 yang berarti bahwa environmental advertisement berpengaruh positif dan signifikan terhadap perilaku pembelian konsumen pada Sariayu Martha Tilaar di Kota Denpasar. Hasil uji F dapat dilihat pada Tabel 4.12, sebagai berikut:

Tabel 10.

Hasil Uji F

\begin{tabular}{llccccc}
\hline & Model & Sum of Square & Df & $\begin{array}{c}\text { Mean } \\
\text { Square }\end{array}$ & F & Sig. \\
\hline $\mathbf{1}$ & Regression & 933,386 & 3 & 311,129 & 82,697 & 0,000 \\
& Residual & 406,328 & 108 & 3,762 & & \\
& Total & 1339,714 & 111 & & & \\
& & & & & & \\
\hline
\end{tabular}

Sumber: data primer diolah, (2017).

Berdasarkan Tabel 4.12 diperoleh F-hitung adalah sebesar 82,697 dengan nilai signifikansi $\mathrm{F}$ sebesar 0,000 lebih kecil dari 5 persen $(\alpha=0,05)$, yang berarti 
bahwa model regresi layak digunakan. Selanjutnya, dapat dilakukan pengujian hipotesis dengan menggunakan uji statistik t (t-test).

Tabel 11.

Hasil Uji T

\begin{tabular}{lcc}
\hline \multicolumn{1}{c}{ Model } & $\mathbf{t}$ & Sig. \\
\hline Eco label $\left(\mathbf{X}_{1}\right)$ & 3,348 & 0,001 \\
Eco brand $\left(\mathbf{X}_{2}\right)$ & 4,831 & 0,000 \\
Environmental advertisement $\left(\mathbf{X}_{3}\right)$ & 3,890 & 0,000 \\
\hline
\end{tabular}

Sumber: data primer diolah, (2017).

Nilai $t_{1}$-hitung adalah 3,348 dengan nilai signifikansi $t_{1}$ sebesar 0,001 lebih kecil dari 5 persen $(\alpha=0,05)$, berarti bahwa terdapat pengaruh yang positif dan signifikan antara eco label terhadap perilaku pembelian konsumen pada Sariayu Martha Tilaar di Kota Denpasar.

Nilai $\mathrm{t}_{2}$-hitung adalah 4,831 dengan nilai signifikansi $\mathrm{t}_{2}$ sebesar 0,000 lebih kecil dari 5 persen $(\alpha=0,05)$, berarti bahwa terdapat pengaruh yang positif dan signifikan antara eco brand terhadap perilaku pembelian konsumen pada Sariayu Martha Tilaar di Kota Denpasar.

Nilai $t_{3}$-hitung adalah 3,890 dengan nilai signifikansi $t_{3}$ sebesar 0,000 lebih kecil dari 5 persen $(\alpha=0,05)$, berarti bahwa terdapat pengaruh yang positif dan signifikan antara environmental advertisement terhadap perilaku pembelian konsumen pada Sariayu Martha Tilaar di Kota Denpasar. Hasil Standardized Coeficients Beta dapat dilihat pada Tabel 12, sebagai berikut:

Tabel 12.

Standardized Coeficients Beta

\begin{tabular}{cccc}
\hline No & Variabel Bebas & Standardized Coeficients Beta & Ranking \\
\hline $\mathbf{1}$ & Eco label $\left(\mathrm{X}_{1}\right)$ & 0,247 & 3 \\
\hline
\end{tabular}




\begin{tabular}{llll}
\hline $\mathbf{2}$ & Eco brand $\left(\mathrm{X}_{2}\right)$ & 0,408 & 1 \\
$\mathbf{3}$ & Environmental advertisement $\left(\mathrm{X}_{3}\right)$ & 0,292 & 2 \\
\hline
\end{tabular}

Sumber: Lampiran 11, (2017).

Tabel 12 menjelaskan bahwa koefisien Beta eco label $\left(\beta_{1}\right)$ sebesar 0,247 (ranking 3), koefisien Beta eco brand $\left(\beta_{2}\right)$ sebesar 0,408 (ranking 1), dan koefisien Beta environmental advertisement $\left(\beta_{3}\right)$ sebesar 0,292 (ranking 2). Jadi, variabel eco brand merupakan variabel dari alat pemasaran hijau yang paling berpengaruh dominan terhadap terhadap perilaku pembelian konsumen pada Sariayu Martha Tilaar di Kota Denpasar.

\section{Pengaruh Eco Label Terhadap Perilaku Pembelian Konsumen}

Hasil pengujian menunjukkan bahwa tingkat signifikansi sebesar 0,001< 0,05 yang berarti bahwa $\mathrm{H}_{1}$ diterima. Hal ini menunjukkan bahwa eco label berpengaruh positif dan signifikan terhadap perilaku pembelian konsumen. Dengan demikian, semakin meningkatnya penerapan eco label, maka akan diikuti oleh meningkatnya perilaku pembelian konsumen pada Sariayu Martha Tilaar di Kota Denpasar. Terdapat 3 (tiga) indikator yang digunakan untuk mengukur eco label, yaitu "Saya memiliki kesadaran akan pentingnya logo pada Sariayu Martha Tilaar yang menginformasikan produk ramah lingkungan", "Saya mudah dalam mengenali logo pada Sariayu Martha Tilaar yang menunjukkan produk ramah lingkungan", dan "Saya mempercayai informasi yang tertera pada logo bahwa Sariayu Martha Tilaar adalah produk ramah lingkungan”.

Hasil penelitian ini mendukung temuan Rahbar dan Wahid (2011), Daria dan Sara (2011), Delafrooz et al. (2014), Taufique et al. (2016), dan Prastiyo (2016), yang menunjukkan bahwa terdapat pengaruh positif dan signifikan antara 
eco label terhadap perilaku pembelian konsumen. Berbeda dengan temuan Putranto (2014) dan Yulindo (2013), yang menunjukkan bahwa terdapat pengaruh positif namun tidak signifikan antara eco label atau label produk terhadap perilaku pembelian konsumen.

\section{Pengaruh Eco Brand Terhadap Perilaku Pembelian Konsumen}

Hasil pengujian menunjukkan bahwa tingkat signifikansi sebesar 0,000< 0,05 yang berarti bahwa $\mathrm{H}_{2}$ diterima. Hal ini menunjukkan bahwa eco brand berpengaruh positif dan signifikan terhadap perilaku pembelian konsumen. Dengan demikian, semakin meningkatnya penerapan eco brand, maka akan diikuti oleh meningkatnya perilaku pembelian konsumen pada Sariayu Martha Tilaar di Kota Denpasar. Terdapat 3 (tiga) indikator yang digunakan untuk mengukur eco brand, yaitu "Saya menyadari akan pentingnya kekuatan merek Sariayu Martha Tilaar yang menunjukkan produk ramah lingkungan”, "Merek Sariayu Martha Tilaar memberikan keyakinan tentang keandalan produk yang ramah lingkungan”, dan "Merek yang digunakan Sariayu Martha Tilaar menjadi daya tarik yang kuat".

Hasil penelitian ini mendukung temuan Rahbar dan Wahid (2011), Delafrooz et al. (2014), Sharma dan Trivedi (2016), dan Anjani dan Aksari (2016), yang menunjukkan bahwa eco brand berpengaruh positif dan signifikan terhadap perilaku pembelian konsumen. Lain halnya dengan temuan Yulindo (2013), yang menunjukkan bahwa merek produk berpengaruh positif tetapi tidak signifikan terhadap perilaku pembelian konsumen. 


\section{Pengaruh Environmental Advertisement Terhadap Perilaku Pembelian Konsumen}

Pengujian hipotesis pada pengaruh terhadap perilaku pembelian konsumen ditemukan terdapat pengaruh positif dan signifikan ditunjukkan dengan tingkat signifikansi sebesar $0,000<0,05$ yang berarti bahwa $\mathrm{H}_{3}$ : environmental advertisement berpengaruh positif dan signifikan terhadap perilaku pembelian konsumen, diterima.

Hal ini menunjukkan bahwa environmental advertisement berpengaruh positif dan signifikan terhadap perilaku pembelian konsumen. Dengan demikian, semakin meningkatnya pelaksanaan environmental advertisement, maka akan diikuti oleh meningkatnya perilaku pembelian konsumen pada Sariayu Martha Tilaar di Kota Denpasar. Terdapat 3 (tiga) indikator yang digunakan untuk mengukur environmental advertisement, yaitu "Sariayu Martha Tilaar menggunakan media yang tepat dalam mempromosikan produknya sebagai produk ramah lingkungan", "Sariayu Martha Tilaar membangun citra sebagai produk ramah lingkungan", dan "Periklanan Sariayu Martha Tilaar mampu memberikan informasi yang dapat menjadi panduan untuk membuat keputusan pembelian".

Hasil penelitian ini mendukung temuan Delafrooz et al. (2014), Anjani dan Aksari (2016), Mantiaha (2016) serta Sharma dan Trivedi (2016), yang menunjukkan bahwa environmental advertisement berpengaruh positif dan signifikan terhadap perilaku pembelian konsumen. Bertolak belakang dengan temuan Rahbar dan Wahid (2011) dan Pawitaningtyas dkk. (2015), yang menunjukkan bahwa environmental advertisement atau yang disebut juga green 
advertising terbukti berpengaruh positif namun tidak signifikan terhadap perilaku pembelian konsumen.

\section{SIMPULAN DAN SARAN}

Berdasarkan hasil pembahasan, dapat ditarik beberapa simpulan, sebagai berikut: Eco label berpengaruh positif dan signifikan terhadap perilaku pembelian konsumen pada Sariayu Martha Tilaar di Kota Denpasar. Eco brand berpengaruh positif dan signifikan terhadap perilaku pembelian konsumen pada Sariayu Martha Tilaar di Kota Denpasar. Environmental advertisement berpengaruh positif dan signifikan terhadap perilaku pembelian konsumen pada Sariayu Martha Tilaar di Kota Denpasar.

Eco brand merupakan alat pemasaran hijau yang berpengaruh dominan terhadap perilaku pembelian konsumen pada Sariayu Martha Tilaar di Kota Denpasar. Ini berarti bahwa penerapan eco brand mampu menunjukkan produk ramah lingkungan yang merupakan alat pemasaran hijau paling berpengaruh terhadap perilaku pembelian konsumen.

Berdasarkan hasil analisis dan simpulan, maka saran yang dapat diberikan kepada pihak manajemen perusahaan diharapkan dapat meningkatkan penerapan eco label dengan mencantumkan informasi yang lebih lengkap dan akurat pada produknya sehingga mampu meningkatkan pengetahuan, kesadaran serta kepercayaan terhadap produk ramah lingkungan dalam mendorong perilaku pembelian konsumen. Perusahaan diharapkan dapat meningkatkan penerapan eco brand dengan memperkuat informasi pada merek produknya sehingga mampu 
meningkatkan kesadaran, keyakinan dan mampu menjadi daya tarik dalam meningkatkan perilaku pembelian konsumen terhadap produk ramah lingkungan. Perusahaan diharapkan dapat meningkatkan pelaksanaan environmental dengan tujuan memberikan informasi seluas-luasnya dan membangun citra sehingga mampu menjadi panduan dalam pengambilan keputusan pembelian konsumen terhadap produk ramah lingkungan.

\section{REFERENSI}

American Marketing Association (AMA). 2009. The American Marketing Association Releases New Definition for Marketing. Ama.org.

Anjani, N., dan Ni Made Asti Aksari. 2016. Pengaruh Green Advertising, Eco Brand, dan Green Trust Terhadap Perilaku Pembelian Produk Hijau di Kota Denpasar. E-Jurnal Manajemen Unud, 5 (5), h: 2814-2841.

Balawera, Asrianto. 2013. Green Marketing dan Corporate Social Responsibility Pengaruhnya Terhadap Keputusan Pembelian Konsumen Melalui Minat Membeli Produk Organik di Fresh Mart Kota Manado. Jurnal EMBA, 1 (4), h: 2117-2129.

Dahlstrom, Roberts. 2011. Green Marketing Management. South-Western: Cengage Learning.

Daria, B., and Khodadad Safaei Sara. 2011. The Influence of Eco-Labeled Products on Consumer Buying Behavior. By Focusing on Organic Fresh Bread. Bachelor Thesis in Business Administration: FOA300, pp: 1-44.

Delafrooz, N., Mohammad Taleghani, and Bahareh Nouri. 2014. Effect of Green Marketing on Consumer Purchase Behavior. QScience Connect, 5, pp: 2-9.

Ekowati, T., dan Murry Harmawan Saputra. 2015. Aplikasi Strategi Green Marketing dengan Studi Kasus Beberapa Perusahaan di Indonesia. SEGMEN Jurnal Manajemen dan Bisnis, 11 (1), h: 17-44.

Kong, W., Harun, A., Sulong, R. S., dan Lily, J. 2014. The Influence of Consumers' Perceprion of Green Products on Green Purchase Intention. International Journal of Asian Social Science, 4 (8), pp: 924-939.

Kotler, Philip and Kevin Lane Keller. 2012. Marketing Manajement. 14th ed. New Jersey: Prentice Hall.

Kotler, Philip dan Gary Armstrong. 2008. Prinsip-prinsip Pemasaran. Edisi 12. Jilid 1. Jakarta: Erlangga. 
Kotler, Philip dan Gary Armstrong. 2008. Prinsip-prinsip Pemasaran. Edisi 12. Jilid 2. Jakarta: Erlangga.

Maheshwari, Shruti P. 2014. Awareness of Green Marketing and Its Influence on Buying Behavior of Consumers: Special Reference to Madhya Pradesh, India. AIMA Journal of Management and Research, 1 (4), pp: 974-497.

Mantiaha, Gratia F. 2016. The Influence of Green Marketing on Consumer Buying Behavior (Study at The Body Shop Manado). Jurnal EMBA, 4 (2), pp: 58-67.

Muslim, E., dan Dyah Rusty Indriani. 2014. Analisis Pengaruh Eco-Label Terhadap Kesadaran Konsumen untuk Membeli Green Product. Jurnal Manajemen Teknologi, 13 (1), h: 66-80.

Parawitha, IGM. Danendra D., dan Ni Made Rastini. 2016. Pengaruh Strategi Green Marketing, Corporate Social Marketing dan Environmental Behavior Terhadap Green Purchasing Behavior. E-Jurnal Manajemen Unud, 5 (10), h: 6457-6486.

Pawitaningtyas, M. R., Srikandi K., dan Sunarti. 2015. Pengaruh Green Advertising Terhadap Citra Merek serta Dampaknya pada Keputusan Pembelian (Survei pada Pengunjung Perpustakaan Umum dan Arsip Kota Malang Konsumen Air Mineral Kemasan Botol Aqua). Jurnal Administrasi Bisnis (JAB), 25 (1), h: 1-7.

Prastiyo, Yuni. 2016. Pengaruh Green Marketing Tool's Terhadap Perilaku Pembelian Konsumen. E-Jurnal Manajemen Unud, 5 (6), h: 3449-3475.

Priyantika, I Gst. Ngr. Ag. Ari., dan I Made Wardana. 2015. Pengaruh Green Advertising dan Green Claim pada Niat Membeli Ulang Konsumen Green Product. E-Jurnal Manajemen Unud, 4 (5), h: 1186-1195.

Putranto, Indra. 2014. Pengaruh Alat Pemasaran Hijau pada Perilaku Pembelian Aktual Konsumen: Studi Empiris pada Lampu Hemat Energi Merek Philips. Skripsi. Universitas Gadjah Mada, Jogjakarta.

Putripeni, Mayang P., Suharyono, dan Andriani Kusumawati. 2014. Pengaruh Green Marketing Terhadap Citra Merek dan Keputusan Pembelian (Studi pada Konsumen The Body Shop Mall Olympic Garden Malang). Jurnal Administrasi Bisnis (JAB), 10 (1), h: 1-10.

Rahbar, E., and Nabsiah Abdul Wahid. 2011. Investigation of Green Marketing Tools Effect on Consumers Purchase Behaviour. Business Strategy Series, 12 (2), pp: 73-83.

Sharma, M., and Prachi Trivedi. 2016. Various Green Marketing Variables and Their Effects on Consumers' Buying Behaviour for Green Products. Amity International Business School, 5 (1), pp: 1-8. 
Suprapti, Ni Made. 2010. Perilaku Konsumen. Denpasar: Udayana University Press.

Taufique, K. M. R., Chamhuri, S., Norshamliza, C., and Farah Hasan Sarah. 2016. Integrating General Environmental Knowledge and Eco-Label Knowledge in Understanding Ecologically Conscious Consumer Behavior. Procedia Economics and Finance, 37, pp: 39-45.

Trisnawati, Rosana. 2016. Pengaruh Atribut-atribut Produk Terhadap Keputusan Pembelian Green Product Cosmetic Sariayu Martha Tilaar (Studi pada Mahasiswa di Bandar Lampung). Skripsi. Fakultas Ekonomi dan Bisnis Universitas Lampung, Bandar Lampung.

www.imacaward.com. Indonesia Most Admired Companies (IMAC) Tahun 2015 dan 2016. (Diakses 19 Maret 2017).

Yulindo, Kenshi Poneva. 2013. Pengaruh Atribut-atribut Produk Terhadap Keputusan Pembelian Green Product Cosmetics Sariayu Martha Tilaar di Kota Padang. Jurnal Manajemen, h: 1-17. 